\title{
Sensitivity analysis of pumping tests in non-uniform aquifers
}

\author{
JIU J. JIAO \\ Department of Geology, University of Alabama, Tuscaloosa, Alabama 35487, \\ $U S A$
}

\begin{abstract}
An approach for better understanding of the physical implication of estimated aquifer parameters is demonstrated by analysing the pumping test data at Cottam in the Nottingham aquifer, UK. A sensitivity analysis showed that the area represented by the estimated parameters was much smaller than the area covered by the depression cone. After parameters are estimated, further research should be carried out to understand what portions of the aquifer the parameters represent. The parameters estimated at Cottam represented mainly aquifer features between roughly 100 and $2000 \mathrm{~m}$. The sensitivity analysis also showed that the observed drawdown being satisfactorily matched by a model with uniform parameters does not prove that the aquifer is homogeneous. Slightly anomalous data may imply the existence of large anomalous zones. Although the drawdowns at Cottam could be 'satisfactorily' fitted by a model with uniform parameters, the fit could be improved by a model using a more permeable aquifer but with a zone about $700 \mathrm{~m}$ wide and with $42 \%$ less transmissivity.
\end{abstract}

\section{Analyse de sensibilité des essais de pompage des aquifères hétérogènes}

Résumé Une tentative permettant de mieux comprendre la signification physique des paramètres estimés d'un aquifère a été entreprise à l'occasion de l'analyse des données d'un essai de pompage réalisé à Cottam dans l'aquifère de Nottingham (Royaume Uni). L'analyse de sensibilité démontre que la région dònt le paramètre estimé est représentatif est en fait beaucoup plus petite que la région couverte par le cône de dépression. Après que les paramètres aient été estimés, des recherches complémentaires devraient être entreprises afin de comprendre de quelle portion de l'aquifère ils sont représentatifs. Les paramètres estimés à Cottam sont essentiellement représentatifs des caractéristiques de l'aquifère entre 100 et $2000 \mathrm{~m}$. Si l'analyse de sensibilité montre que le rabattement observé peut être expliqué par un modèle d'aquifère homogène, ceci n'est pas une preuve de l'homogénéité de l'aquifère. Des données légèrement anormales peuvent impliquer l'existence d'une importante zone anormale. Quoique le rabattement à Cottam puisse être ajusté de manière satisfaisante grâce à un modèle homogène, l'ajustement peut être amélioré grâce à un modèle supposant un aquifère plus perméable mais comportant une zone d'environ $700 \mathrm{~m}$ de large dont la transmissivité serait de $42 \%$ inférieure.

\section{INTRODUCTION}

Analysis of pumping tests based on the Theis equation under the assumptions of homogeneity and isotropy has been practised for decades. The usefulness of 
parameters resulting from a conventional pumping test analysis has been discussed by a number of researchers. For example, Butler (1988) and Butler \& Liu (1993) derived analytical solutions for aquifers with a circular disk of anomalous properties. They concluded that the change in drawdown is sensitive to the hydraulic properties of a discrete portion of an aquifer for a time of limited duration. At large times, drawdown is independent of near-well properties.

Numerical models have also been used to address the non-uniqueness of parameter estimation in terms of pumping test analysis. Butler \& McElwee (1990) investigated the uncertainty problem in a radially symmetrical nonuniform aquifer, with emphasis on finding a more rigorous methodology for pumping test design and analysis. Based on the sensitivity analysis of drawdown to parameters in different zones, they concluded that conventional pumping tests were of limited effectiveness for defining the spatial distribution of aquifer properties and suggested that a variable-rate pumping test can increase the sensitivity of anomalous zones. Another important conclusion from their study was that a parameter can be properly estimated when its sensitivity is not only significant but also changing with time.

An approach for better understanding of the physical implications of estimated aquifer parameters is demonstrated in this paper by analysing the pumping test data at Cottam in the Nottingham aquifer, UK. The sensitivity features of aquifer parameters in radially symmetrical non-uniform aquifers are the theoretical basis of the discussion. It will be shown that the area represented by the estimated parameters is much smaller than the area covered by the depression cone. Therefore, when parameters are estimated by analysing pumping data, it is natural to ask what portions of the aquifer the parameters may represent. The analysis of the general sensitivity features of a non-uniform aquifer will also show that observed drawdown being satisfactorily matched by a model with uniform parameters does not prove that the aquifer is homogeneous. Slightly anomalous data may imply the existence of very large anomalous zones. Therefore, after a pumping test, any anomalous readings should be carefully examined for an indication of possible anomalous zones.

A numerical model specially designed by Rushton \& Chan (1976) for analysing pumping test data is used in this study. In their model, the radial dimension is divided into discrete intervals that increase logarithmically. In the following section, this model is modified to examine the features of parameter sensitivity in non-uniform aquifers.

\section{SENSITIVITY EQUATIONS}

Sensitivity analysis is the study of a system's response to various disturbances. In this study, the disturbances of transmissivity $T$ and storativity $S$ to drawdown $s$ are considered. Mathematically, the sensitivity is a partial derivative which represents the change in head or drawdown resulting from a change in 
a model parameter. For example, the sensitivity of drawdown to $T$ can be defined as:

$$
U_{T}=\partial s / \partial T
$$

A disadvantage of the sensitivity defined by equation (1) is that its magnitude depends on the dimensions and unit of the parameter. A normalized sensitivity can be defined as (e.g. McElwee, 1987):

$$
U_{T}^{\prime}=T \partial s / \partial T=\partial s /(\partial T / T)
$$

This equation demonstrates that normalized sensitivity describes the influence of ratio changes in parameters. Thus, normalized sensitivities can readily be plotted together and compared. The storativity sensitivity $U_{S}$, or normalized storativity sensitivity $U_{S}^{\prime}$, can be defined in the same way. In terms of parameter estimation, the absolute magnitude of a sensitivity, not its signed value, is of importance. When the word sensitivity is used hereafter, it means the absolute magnitude of sensitivity.

As the drawdown can be solved as a function of distance and time in response to defined initial and boundary conditions, the sensitivity of drawdown to a parameter can be also solved as a function of distance and time in response to the same conditions (McElwee \& Yukler, 1978). For confined, radial flow of groundwater to a pumping well, the flow can be represented by the following equation:

$$
\frac{\partial}{\partial r}\left[T(r) \frac{\partial s}{\partial r}\right]+\frac{T(r)}{r} \frac{\partial s}{\partial r}=S(r) \frac{\partial s}{\partial t}
$$

with

$$
\left.\begin{array}{lr}
s(r, 0)=0 & r_{w} \leq r<\infty \\
s(\infty, t)=0 & t>0 \\
\left.\frac{\partial s}{\partial r}\right|_{r_{w}}=\frac{-Q}{2 \pi r_{w} T} & t>0
\end{array}\right\}
$$

where $T(r)$ and $S(r)$ are transmissivity and storativity, $s(r, t)$ is drawdown, $r$ is radial distance, $r_{w}$ is well radius, $Q$ is pumping rate, and $t$ is time.

Introducing a radial variable $a=\ln r$, equation (3) then becomes (Rushton \& Chan, 1976):

$$
\frac{\partial}{\partial a}\left[T(r) \frac{\partial s}{\partial a}\right]=r^{2} S(r) \frac{\partial s}{\partial t}
$$

The sensitivity of drawdown at a given observation point to transmissivity and storage at any point within the aquifer can be calculated using the following equations: 


$$
\begin{aligned}
\frac{\partial}{\partial a}\left[T(r) \frac{\partial U_{T}\left(r, t ; r_{s}\right)}{\partial a}\right] & =r^{2} S(r) \frac{\partial U_{T}\left(r, t ; r_{s}\right)}{\partial t}-\frac{\partial}{\partial a}\left[\Delta\left(r-r_{s}\right) \frac{\partial s}{\partial a}\right] \\
\frac{\partial}{\partial a}\left[T(r) \frac{\partial U_{S}\left(r, t ; r_{s}\right)}{\partial a}\right] & =r^{2} S(r) \frac{\partial U_{S}\left(r, t ; r_{s}\right)}{\partial t}+r^{2}\left[\Delta\left(r-r_{s}\right) \frac{\partial s}{\partial t}\right]
\end{aligned}
$$

where $U_{T}\left(r, t ; r_{s}\right.$ is the sensitivity of drawdown at $(r, t)$ to transmissivity at $r_{s}$, equal to $\partial s(r, t) / \partial T\left(r_{s}\right) ; U_{S}\left(r, t ; r_{s}\right)$ is the sensitivity of drawdown at $(r, t)$ to storativity at $r_{s}$, equal to $\partial s(r, t) / \partial S\left(r_{s}\right) ; \Delta\left(r-r_{s}\right)$ is a modified dimensionless delta function which equals unity when $r=r_{s}$, zero otherwise (Butler \& McElwee, 1990).

Equations (6) \& (7) are obtained by taking the derivative of drawdown $s(r, t)$ to the transmissivity and storativity at $r_{s}$. The similarity of the form of equations (6) and (7) to that of equation (5) enables the computer code used for the solution of equation (5) to be utilized for sensitivity analysis following minimal modification. Detailed discussion of the solutions of these two equations can be found in McElwee (1987).

\section{SENSITIVITY FEATURES OF A RADIALLY NON-UNIFORM AQUIFER}

After the sensitivity equations for non-uniform aquifers are developed, the sensitivity features of drawdown to parameters in a radial two-zone aquifer and an aquifer with an anomalous zone will be discussed by using two hypothetical examples.

\section{Sensitivity of parameters in a radial two-zone aquifer}

Consider an aquifer with two zones. The aquifer configuration, well locations and parameters are shown in Fig. 1(a). The pumpage is $2500 \mathrm{~m}^{3}$ day ${ }^{-1}$.

Figure 2(a) shows how the normalized sensitivity of the dimensionless drawdown $\left[\left(4 \pi T_{2} s\right) / Q\right]$ to $S_{1}$ changes with dimensionless time $\left(T_{2} t / S_{2} r_{0}^{2}\right)$ in the two observation wells. The sensitivity increases to a maximum at a few seconds and then gradually decreases to zero. The sensitivity at $17.8 \mathrm{~m}$ is much smaller than that at $4.2 \mathrm{~m}$ and the maximum is achieved much later. The maximum sensitivity decreases markedly with the increase in distance between the observation and pumping wells. Both sensitivities become virtually zero after $t=100$ (about 0.001 day). After that, the drawdown is insensitive to $S_{1}$.

Figure 2(b) shows the normalized sensitivity of the dimensionless drawdown to $T_{1}$ in the two observation wells. It increases very quickly at $4.2 \mathrm{~m}$ when pumping begins and becomes almost constant after $t=100$, which is also the time when the sensitivity to storativity becomes almost zero. As 

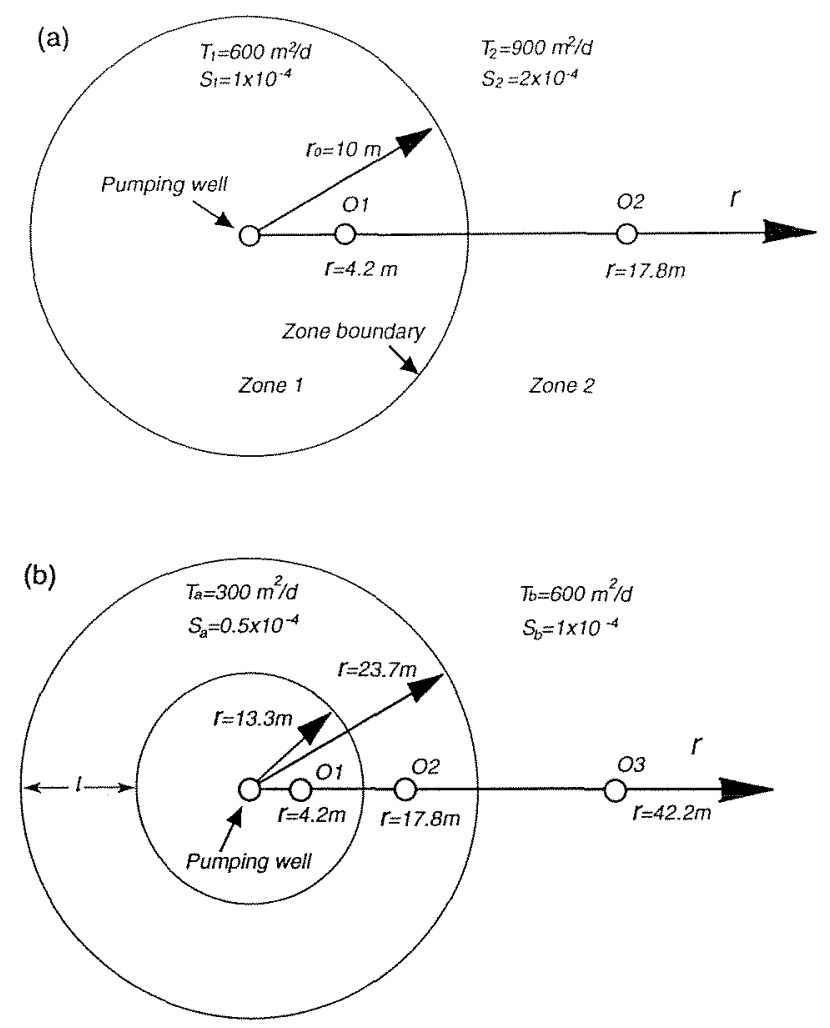

Fig. 1 Schematic representation of aquifers with radially symmetrical anomalous zones.

discussed by Butler \& McElwee (1990), the data in a period when the sensitivity of a parameter is constant will not help much in estimating the parameter. Therefore, in terms of estimating transmissivity in Zone 1, drawdown data should also be collected in the very short time when the transmissivity sensitivity changes significantly with time. Figure 2(b) also shows that the sensitivity of the drawdown in Zone 2 (at $r=17.8 \mathrm{~m}$ ) to $T_{1}$ changes with time. The sensitivity is very small and soon becomes zero. The reasons for the small positive value were discussed by Jiao (1993). In terms of parameter estimation, it implies that $T_{1}$ is very difficult to estimate using the drawdown in Zone 2.

The observation wells in the above example are very near the pumping well. In a real pumping test, they are usually further away. It may be impossible for the sensitivity features of a zone very near the pumping well to be displayed in the observation wells. Even when the non-uniform zone near the pumping well is at a distance of a few tens of metres, close attention is still needed to take readings in the observation wells during the very early observation periods if the aquifer features of the zone are to be examined. Similar conclusions were also made by Butler \& Liu (1993). 

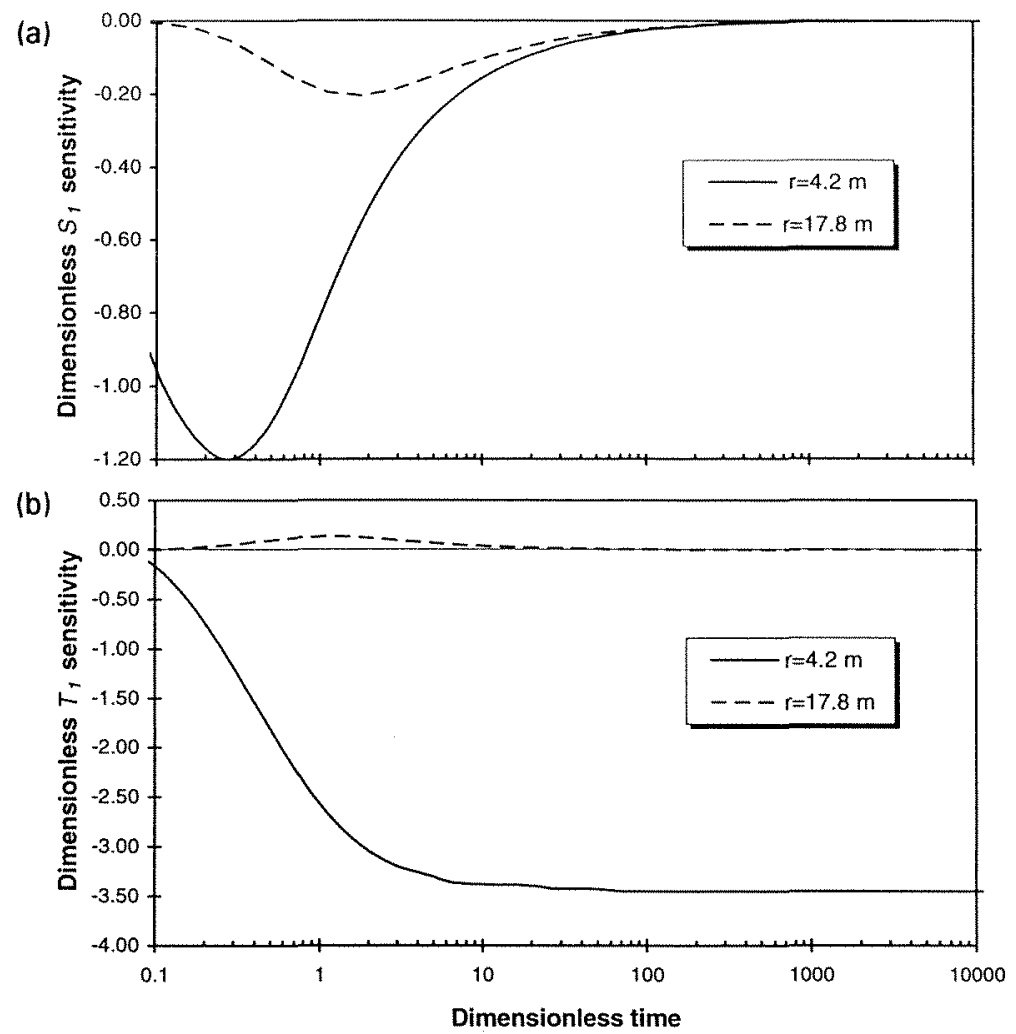

Fig. 2 Normalized sensitivities of dimensionless drawdowns $\left[\left(4 \pi T_{2} s\right) / Q\right]$ in inner and outer zones to (a) storativity and (b) transmissivity of inner zone changing with dimensionless time $\left(T_{2} t / S_{2} r_{0}^{2}\right) . \quad\left(T_{1}=600 \mathrm{~m}^{2}\right.$ day $^{-1}$, $S_{1}=1 \times 10^{-4}, T_{2}=900 \mathrm{~m}^{2} \mathrm{day}^{-1}, S_{2}=2 \times 10^{-4}$ ).

\section{Sensitivity of parameters in a radial anomalous zone aquifer}

Consider now an aquifer with an annular zone. The aquifer configuration, well locations and parameters are shown in Fig. 1(b). The pumpage remains the same as in the first case.

Assume that the background aquifer has parameters $T_{b}=600 \mathrm{~m}^{2}$ day ${ }^{-1}$ and $S_{b}=1 \times 10^{-4}$ and that the annular zone has parameters $T_{a}=300 \mathrm{~m}^{2}$ day $^{-1}$ and $S_{a}=0.5 \times 10^{-4}$. Figure 3(a) shows how the normalized sensitivity of the dimensionless drawdown $\left[\left(4 \pi T_{b} s\right) / Q\right.$ ] to $S_{a}$ changes with dimensionless time $\left(T_{b} t / S_{b} l^{2}\right)$. For all three observation wells, the plot of sensitivity against logtime gives bell-shaped curves. This means that the influence of the parameters of the zone only covers a limited time. The sensitivities at $r=4.2$ and $17.8 \mathrm{~m}$ are not very different, but the sensitivity at $r=42.2 \mathrm{~m}$ is much smaller.

Figure 3(b) shows how $U_{T a}^{\prime}$ (the normalized sensitivity of the dimensionless drawdown to zone transmissivity) changes with time. The sensitivity is largest for the well at $4.2 \mathrm{~m}$, though that in the well located in the zone is 


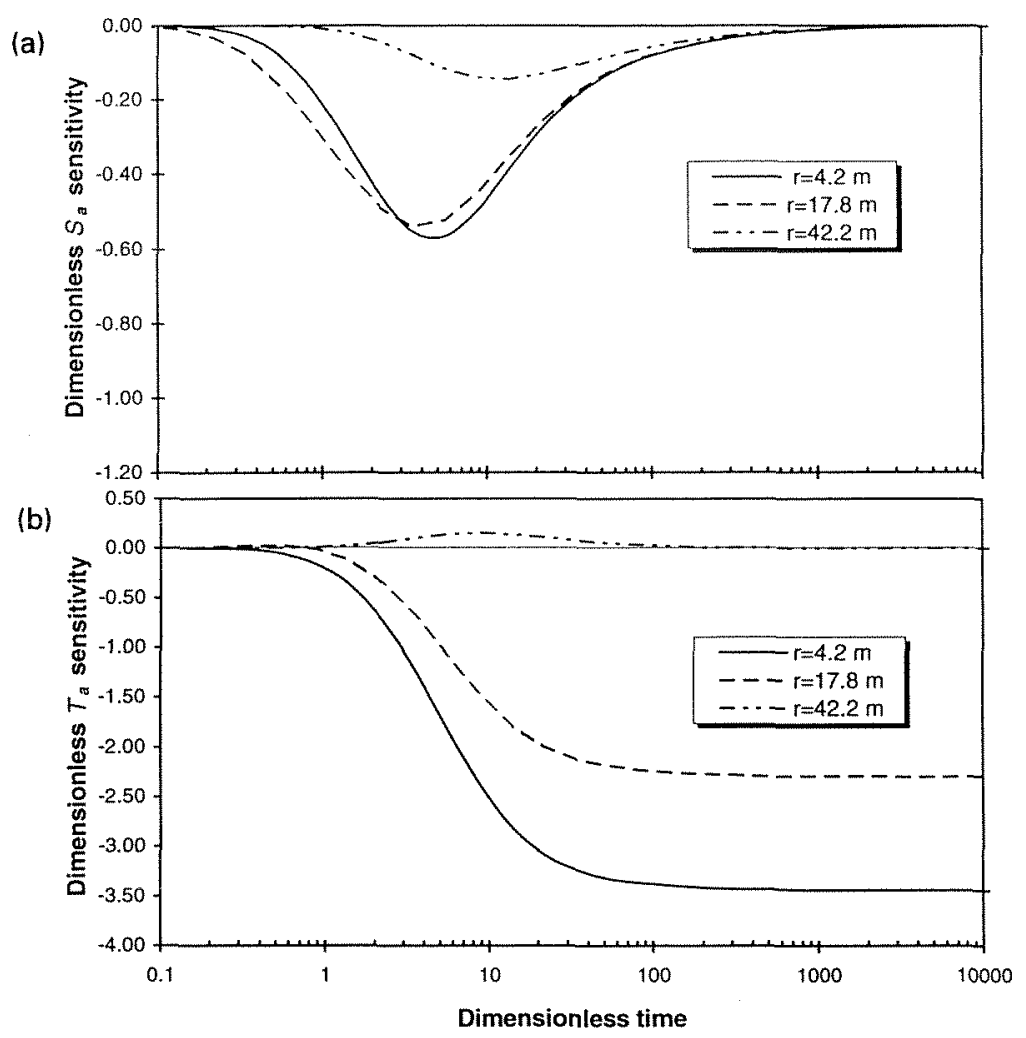

Fig. 3 Normalized sensitivities of dimensionless drawdowns $\left[\left(4 \pi T_{b} s\right) / Q\right]$ in inner aquifer, anomalous zone and outer zones of Fig. 1(b) to (a) storativity and (b) transmissivity of zone changing with dimensionless time $\left(T_{b} t / S_{b} l^{2}\right)$. $\left(T_{b}=600 \mathrm{~m}^{2}\right.$ day $^{-1}, S_{b}=1 \times 10^{-4}, T_{a}=300 \mathrm{~m}^{2}$ day $\left.^{-1}, S_{a}=0.5 \times 10^{-4}\right)$.

comparable. In contrast, the sensitivity of the well at $42.2 \mathrm{~m}$ is very small. It approaches a maximum and then decreases to zero at the time when the sensitivity of the other two wells approaches constant values.

\section{SENSITIVITY CHANGES WITH DISTANCE OF AN ANOMALOUS ZONE}

Consider a less permeable annular zone about $30 \mathrm{~m}$ wide, with transmissivity $300 \mathrm{~m}^{2}$ day $^{-1}$ and storativity $0.5 \times 10^{-4}$ (equal to half of the values for the background aquifer). An observation well is located at $4.2 \mathrm{~m}$. The influence of the zone on the observed drawdown is expected to change with the location of the zone. Figure 4 shows the sensitivity of drawdown to (a) storativity and (b) transmissivity in the less permeable zone when it starts at 13.3, 42.2 and $100 \mathrm{~m}$ from the pumping well, respectively. The sensitivities decrease with increasing distance of the zone from the observation well. The more distant the zone is from the observation well, the less the drawdown will reflect the 
change in the flow properties of the zone. Very often, for a long pumping test, the readings at later times are only taken at intervals of several hours. The magnitude of the sensitivity of drawdown to the flow properties of the distant zone is then so small, and the time interval of the sensitivity so short, that the influence of the zone on the drawdown in the observation well can very easily be missed. However, slight changes in the drawdown at the observation well may imply a large anomalous zone far away. The slight changes are often treated as a measuring error and then ignored. Therefore, an almost standard response of drawdown in an observation well near the pumping well in a long pumping test does not prove that the aquifer is homogeneous.

(a)

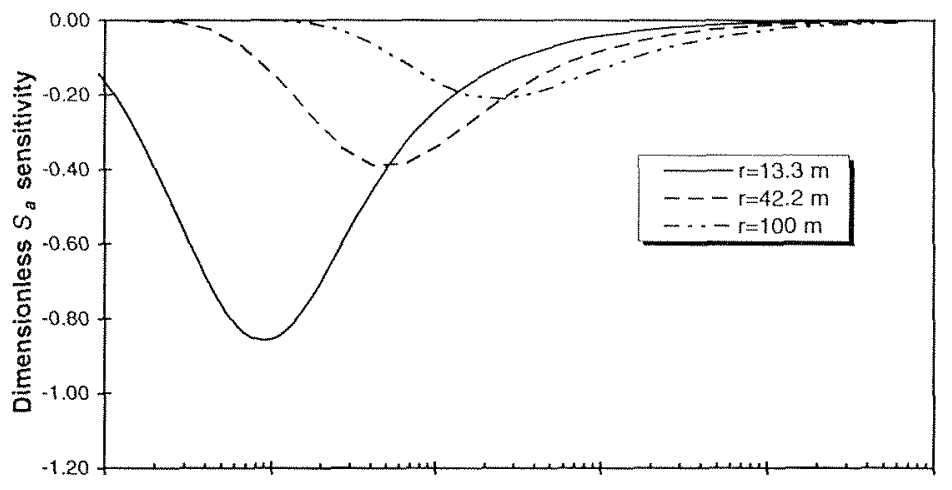

(b)

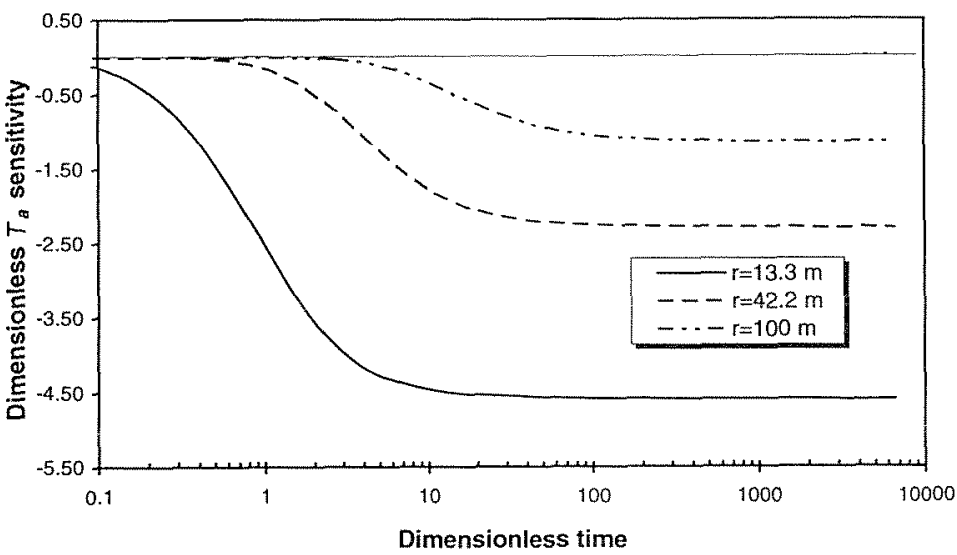

Fig. 4 Normalized sensitivities of dimensionless drawdowns $\left[\left(4 \pi T_{b} s\right) / Q\right]$ at $r=4.2 \mathrm{~m}$ to (a) storativity and (b) transmissivity of $30 \mathrm{~m}$ zone of Fig. 1(b) changing with dimensionless time $\left(T_{b} t / S_{b} l^{2}\right) .\left(T_{b}=600 \mathrm{~m}^{2}\right.$ day $^{-1}, T_{a}=300$ $\mathrm{m}^{2}$ day $^{-1}, S_{b}=1 \times 10^{-4}, S_{a}=0.5 \times 10^{-4}$ ).

\section{PARAMETER ESTIMATION IN RADIALLY NON-UNIFORM AQUIFERS}

Two hypothetical examples are now used to investigate the influence of anomalous zones on parameter estimation by coupling the radial numerical flow 
model with the Gauss-Newton optimization method. The objective function is presented as the sum of the squares of the differences between the 'observed' and calculated drawdowns. The aquifer configuration used in the examples is the same as that in Fig. 1(b) except for the particular locations of the zones and the observation wells.

\section{Example 1}

Example 1 will show that the parameters estimated from an observation well near the pumping well cannot reflect the effect of an anomalous zone while at a distance but still in the area appreciably influenced by the pumping, even when the flow parameters are significantly different from those of the background aquifer.

Assume the aquifer contains an annular zone between $r=100$ and $133 \mathrm{~m}$. The background aquifer parameters are $T_{b}=600 \mathrm{~m}^{2}$ day $^{-1}$, $S_{b}=1 \times 10^{-4}$. An observation well is at $r=4.2 \mathrm{~m}$, which is very near the pumping well and far from the zone. The influence of the zone on parameter values estimated from the observation well is investigated as follows: drawdown data are created by running the flow model with the zone included, and the data are then used as the 'observed' drawdown to estimate the parameters by running the optimization model coupled with the same flow model but excluding the zone.

Consider first when the zone parameters are half those of the background. The estimated uniform parameters are presented in the third row of Table 1, which shows that the drawdown from the aquifer with parameters $T_{b}=600 \mathrm{~m}^{2}$ day $^{-1}$ and $S_{b}=0.5 \times 10^{-4}$, including a $33 \mathrm{~m}$ wide zone of parameters $T_{a}=300 \mathrm{~m}^{2}$ day $^{-1}$ and $S_{a}=0.5 \times 10^{-4}$ at $100 \mathrm{~m}$, can be reproduced by an equivalent aquifer with uniform parameters $T=563.0 \mathrm{~m}^{2}$ day $^{-1}$ and $S=1.11 \times 10^{-4}$. All the estimated parameters when the zone parameters vary from $-83 \%$ to $+83 \%$ of the background aquifer parameters are listed in Table 1 . When a zone of smaller parameters than the background is ignored,

Table 1 Estimated parameters in an equivalent model changing with the zone transmissivity and storativity

\begin{tabular}{lllllllll}
\hline $\begin{array}{l}\text { Zone parameters } \\
T\left(\mathrm{~m}^{2} \text { day }^{-1}\right)\end{array}$ & $10^{4} S$ & Diff. (\%) & $T\left(\mathrm{~m}^{2}\right.$ day $)$ & Diff. $(\%)$ & $10^{4} S$ & Diff. (\%) & $(4.2 \mathrm{~m})$ & $(100 \mathrm{~m})$ \\
\hline 100 & 0.166 & -83 & 449.4 & -25.1 & 1.69 & +69 & 5.40 & 3.31 \\
200 & 0.333 & -67 & 530.2 & -11.6 & 1.24 & +24 & 4.84 & 2.74 \\
300 & 0.500 & -50 & 563.0 & -2.8 & 1.11 & +11 & 4.64 & 2.55 \\
900 & 1.500 & +50 & 613.8 & +2.3 & 0.97 & -3 & 4.39 & 2.29 \\
1000 & 1.666 & +67 & 616.7 & +2.8 & 0.96 & -4 & 4.37 & 2.28 \\
1100 & 1.833 & +83 & 619.2 & +3.2 & 0.96 & -4 & 4.36 & 2.27 \\
\hline
\end{tabular}

$s_{1}$ and $s_{2}$ are the drawdowns at $r=4.2$ and $100 \mathrm{~m}$ respectively, at $t=1$ day, calculated from the model including the zone.

Diff.: percentage departure from background. 
the estimated transmissivity in the equivalent uniform aquifer is reduced, and storativity increased. However, the deviation from the true background parameters is very small compared to the difference between the zone and the background parameters.

When the zone parameters are only half those of the background values, the aquifer as a whole may be considered to be very non-uniform. However, as shown in Table 1 , the estimated transmissivity and storativity differ by only $2.8 \%$ and $11 \%$ from the background parameters. This means that a $33 \mathrm{~m}$ low permeable zone at $100 \mathrm{~m}$ does not make much difference in estimating the general aquifer parameter values. When the zone is more permeable, the influence is even smaller. Table 1 shows that the estimated parameter transmissivity and storativity differ by only $3.2 \%$ and $4 \%$ from the background values even when transmissivity and storativity of the zone are $83 \%$ larger. This indicates that a significantly more permeable zone of $33 \mathrm{~m}$ width at $r=100 \mathrm{~m}$ has virtually no influence on parameter estimation in the observation well near the pumping well.

It may be argued that the influence of the zone on parameter values estimated from the observation well is negligible because the zone is far away and drawdown there may be very small. This is not the case. In the last two columns of Table 1, the drawdowns at $r=4.2 \mathrm{~m}$ and $r=100 \mathrm{~m}$ at the end of pumping are listed. The drawdowns at $r=100 \mathrm{~m}$ are more than half the drawdowns at the observation well. The zone is therefore significantly influenced by the pumping during the pumping period.

Table 2 Comparison of drawdowns (m) from true and equivalent models

\begin{tabular}{cllll}
\hline Time & \multicolumn{2}{l}{$r=4.2 \mathrm{~m}$} & \multicolumn{2}{l}{$r=100 \mathrm{~m}$} \\
(min.) & True model & Equivalent model & \multicolumn{2}{l}{ True model Equivalent model } \\
\hline 0.0144 & 0.664 & 0.654 & 0.000 & 0.000 \\
0.144 & 1.404 & 1.437 & 0.005 & 0.002 \\
1.44 & 2.219 & 2.247 & 0.298 & 0.189 \\
14.4 & 3.116 & 3.061 & 1.034 & 0.844 \\
144 & 3.884 & 3.874 & 1.787 & 1.639 \\
1440 & 4.646 & 4.688 & 2.547 & 2.451 \\
\hline
\end{tabular}

It may also be argued that the estimated parameters from the flow model without the zone may not fit well the 'observed' data generated from the flow model including the zone. Table 2 lists the drawdowns estimated from the equivalent aquifer with uniform parameters $T=563.0 \mathrm{~m}^{2}$ day ${ }^{-1}$ and $S=1.11 \times 10^{-4}$ and the drawdowns 'observed' from the aquifer with 'true' parameters $T_{b}=600 \mathrm{~m}^{2}$ day $^{-1}$ and $S_{b}=1 \times 10^{-4}$ and a much less permeable zone with $T_{a}=300 \mathrm{~m}^{2}$ day $^{-1}$ and $S_{a}=0.5 \times 10^{-4}$. The difference between the drawdowns at $r=4.2 \mathrm{~m}$ is so small that, if shown by a plot, there is no visual difference. The drawdowns at $r=100 \mathrm{~m}$, however, show some substantial differences. Without the drawdown information of the well near the zone, there would be no reason to challenge the results for the well at $4.2 \mathrm{~m}$ predicted by 
Table 3 Estimated parameters in equivalent model change into background flow properties with zone parameters fixed $\left(T_{a}=600 \mathrm{~m}^{2}\right.$ day $^{-1}$; $S_{a}=1 \times 10^{-4}$ )

\begin{tabular}{llllll}
\hline Background parameters & \multicolumn{4}{l}{ Estimated $T$ and $S$} \\
$T\left(\mathrm{~m}^{2}\right.$ day $\left.^{-1}\right)$ & $10^{4} S$ & $T\left(\mathrm{~m}^{2}\right.$ day & Diff. (\%) & $10^{4} S$ & Diff. (\%) \\
\hline 300 & 0.5 & 311.1 & +3.7 & 0.47 & -6.0 \\
900 & 2.0 & 869.2 & -3.4 & 2.11 & +5.5 \\
\hline
\end{tabular}

the equivalent model of uniform parameters.

When a large anomalous zone with considerably different parameters is ignored, the drawdown in the observation well near the pumping well can still produce estimated parameters very close to the background values. The estimated parameters can barely indicate the hydraulic effect of a limited anomalous zone at a considerable distance but still within the area significantly influenced by the pumping. The fact that the drawdown in an observation well can be fitted satisfactorily by a model with uniform flow properties does not justify concluding that the aquifer is homogeneous.

In the above cases, the background aquifer parameters were maintained at $T_{a}=600 \mathrm{~m}^{2}$ day $^{-1}$ and $S_{a}=1 \times 10^{-4}$. Now the zone parameters take those values, but the background aquifer is given first $T_{b}=300 \mathrm{~m}^{2}$ day ${ }^{-1}$, $S_{b}=0.5 \times 10^{-4}$ and then $T_{b}=900 \mathrm{~m}^{2}$ day $^{-1}, S_{b}=2 \times 10^{-4}$. The parameters estimated from a model of uniform parameters, to fit the drawdown created by the model with the zone, are as shown in Table 3. When the background aquifer is more permeable, the difference between the estimated equivalent parameters and the background parameters is smaller. For a more permeable aquifer, the influence of an anomalous zone is less significant and the error in estimated background aquifer parameters is smaller when the zone is ignored. However, in both cases, the difference between the equivalent parameters and background aquifer parameters is very small and does not change much with background parameters.

The above conclusion that the influence of the anomalous zones is not significant is true only when the transmissivity of the background aquifer is typical. If the transmissivity is very small, it can be expected (based on Table 3) that the anomalous zones may become important. As will be demonstrated in the Nottingham case study later, the transmissivity is generally less than $80 \mathrm{~m}^{2}$ day $^{-1}$; the parameters estimated may be significantly different when an anomalous zone is ignored.

\section{Example 2}

In Example 2, the influence of an anomalous zone near the pumping well on the parameters estimated from an observation well away from the pumping well will now be analysed. 
The aquifer configuration remains the same (Fig. 1(b)), except that an anomalous zone is located between $r=2.4$ and $10.0 \mathrm{~m}$ and the observation well is located at $r=56.2 \mathrm{~m}$. When the parameters in the zone vary from $-83 \%$ to $+83 \%$ of the background values, the estimated parameters are very similar to the background aquifer parameters (Table 4).

When the observation well is moved to 31.6 and then to $13.3 \mathrm{~m}$, the estimated transmissivity is gradually reduced and the storativity is gradually increased when the zone is more permeable than the background aquifer. The changes are reversed when the zone is less permeable. In both cases, the change in $T$ is smaller than that in $S$. Generally, the influence of the zone is small. Even when the well is only about $3 \mathrm{~m}$ from the zone, the estimated parameters using an equivalent model are still very close to the background values (Table 4).

Table 4 Estimated parameters using equivalent model changing with the distance from the observation well to the anomalous zone with parameter values $83 \%$ larger or $83 \%$ smaller than the background parameters $\left(T=600 \mathrm{~m}^{2}\right.$ day $\left.^{-1} ; S=1 \times 10^{-4}\right)$

\begin{tabular}{lllllll}
\hline Zone & $r=52.6 \mathrm{~m}$ & \multicolumn{3}{c}{$r=31.6 \mathrm{~m}$} & $r=13.3 \mathrm{~m}$ \\
parameters & $T\left(\mathrm{~m}^{2}\right.$ day $\left.^{-1}\right)$ & $S$ & $T\left(\mathrm{~m}^{2}\right.$ day $\left.^{-1}\right)$ & $S$ & $T\left(\mathrm{~m}^{2}\right.$ day & \\
\hline$-83 \%$ & 601.3 & 0.99 & 602.3 & 0.97 & 604.0 & $S$ \\
$+83 \%$ & 598.6 & 1.01 & 596.9 & 1.03 & 593.2 & 0.95 \\
\hline
\end{tabular}

\section{PUMPING TEST DATA ANALYSIS AT COTTAM}

The above discussion shows that the features of the portions of an aquifer that are away from the observation well may not be reflected by the estimated parameters because of insensitivity. The area represented by the estimated parameters may be much smaller than the area covered by the depression cone. Another implication from the above discussion is that the sensitivity period of an anomalous zone is so short that one or two anomalous readings may mean the existence of a large anomalous zone. For a pumping test, it may be important to understand what portions of the aquifer the estimated parameters primarily represent and to examine any anomalous readings for indication of possible anomalous zones. The approach to estimate the possible area represented by the estimated parameters and to understand the implication of the anomalous readings will be demonstrated using the pumping test data in the Nottingham aquifer, UK.

The numerical model with radially symmetrical aquifer configurations will be used again. This model is not very realistic in representing a real heterogeneous aquifer, but it is believed that the following approach based on this model will lead to a better understanding of the estimated parameters and provide a general methodology to re-analyse traditional pumping test data. 


\section{Brief description of pumping test at Cottam}

A pumping test was conducted at Cottam in the Nottingham aquifer in 1984. The tested aquifer is Sherwood Sandstone. Eastwards, the aquifer gently dips conformably under the Mercia Mudstones, at approximately $2-3^{\circ}$, and extends to well outside the study area. The Mercia Mudstones overlie the sandstones and, being less permeable, act as a confining horizon. The westward margin of the aquifer is the Permian Magnesian Limestone series (Fig. 5) with coal measures, which underlies the aquifer and acts essentially as a markedly less permeable horizon (Rushton \& Bishop, 1993).

Both pumping and observation wells were drilled to the same depth of $430 \mathrm{~m}$. The distance between them was $225 \mathrm{~m}$. During testing, the aquifer remained confined. The analysis is based on the data from the observation well. The observed data within 46 days were used for this study. The pumping rate was $4600 \mathrm{~m}^{3}$ day $^{-1}$.

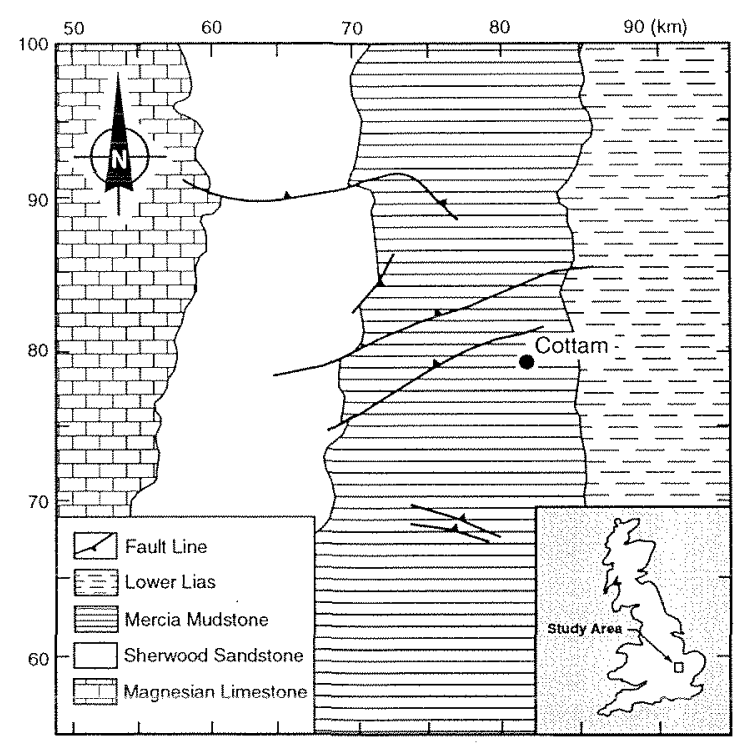

Fig. 5 Schematic geological map of the pumping test site (modified from Rushton \& Bishop, 1993).

\section{Possible area represented by estimated parameters}

The drawdowns are presented in Fig. 6(a). The estimated parameters and the objective function (obj.) were $T=54.34 \mathrm{~m}^{2}$ day $^{-1}, \quad S=3.80 \times 10^{-4}$, obj. $=6.93$. As shown in Fig. 6(a), the fit seemed very satisfactory.

Estimated parameters represent mainly the features of the portions of the aquifer to which they are sensitive during the test period. The approach to examine which portions of the aquifer the estimated parameters represent is like 


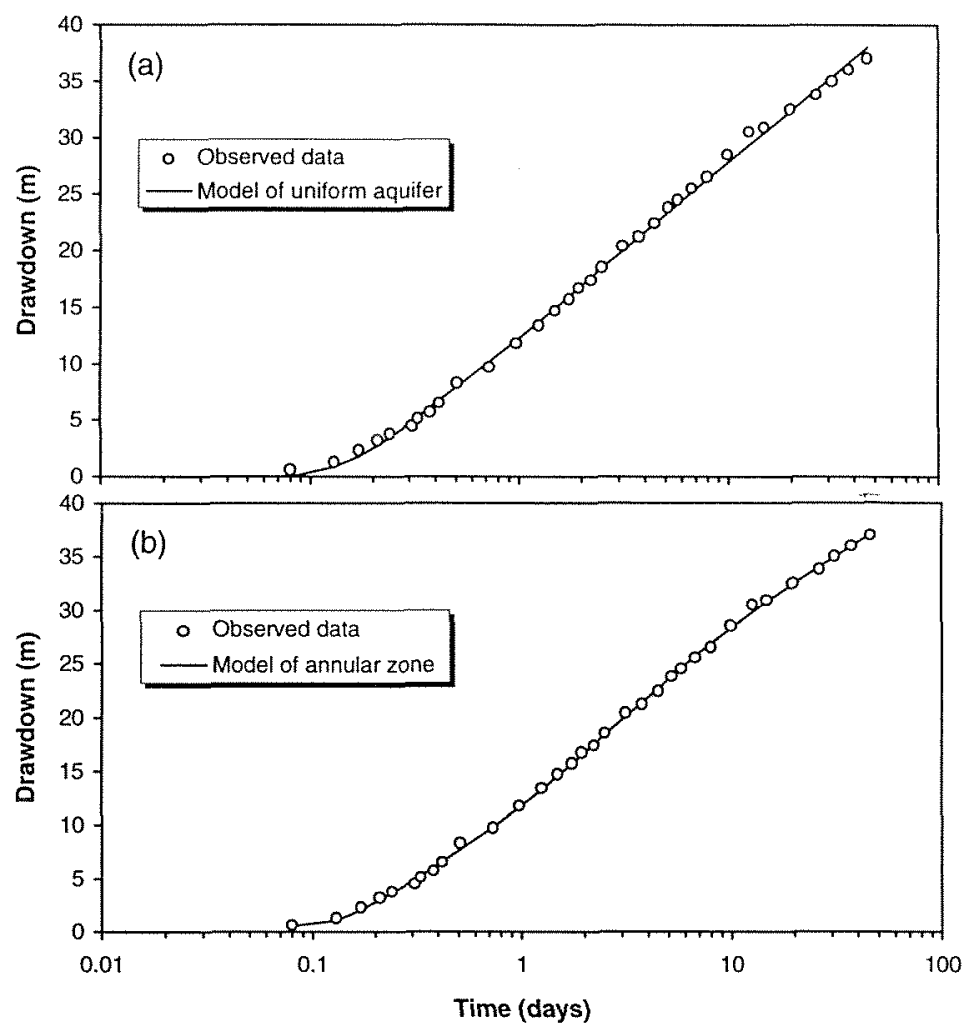

Fig. 6 Comparison of observed and calculated drawdowns at Cottam.

that used for Fig. 1(a), where the aquifer was divided into two zones. First, assume the inner zone is small and then examine the sensitivity of drawdown to the parameters of the inner zone (see Fig. 7(a)). If the sensitivity is very small, and the sensitive period occurs earlier than the observation period (shown in Fig. 6(a)), the estimated parameters will not reflect the inner zone's features much. Next, the zone boundary is chosen to be very distant and the sensitivity features of the parameters of only the outer zone are investigated (see Fig. 7(b)). If the parameter sensitivity of the outer zone begins to be significant at the end of, or after the end of, the observation period, the features of the zone cannot be reflected much by the observed data. In this way, the portion of the aquifer for which the estimated parameters are primarily representative can be roughly estimated (Fig. 7).

The storativity sensitivity of a zone ending within a few tens of metres of the pumping well was first examined. In Fig. 8(a), the continuous line shows how the storativity sensitivity of the inner zone changed with time when the zone was within $32 \mathrm{~m}$ of the well. The curve is flat and the values are very small. When the zone width (or zone boundary) was progressively increased to $75 \mathrm{~m}$, the sensitivity gradually increased. However, the duration of the sensitive period did not increase much. The most sensitive period of the zone within $75 \mathrm{~m}$ was from 0.07 to 0.3 day, but only about five drawdown readings 


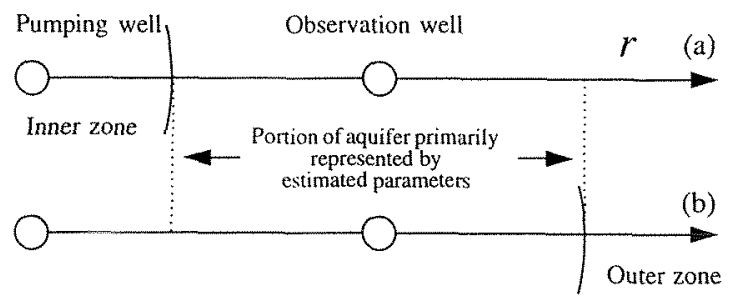

Fig. 7 Schematic representation of (a) inner and (b) outer zones which may not be properly reflected by estimated parameters in observation well and portion of aquifer mainly represented by estimated parameters.

were taken during this period (Fig. 6(a)). It is therefore unlikely that the estimated storativity, based on the drawdown in the observation well in the period of 46 days, reflected the features of much of the inner zone even if it was $75 \mathrm{~m}$ wide.
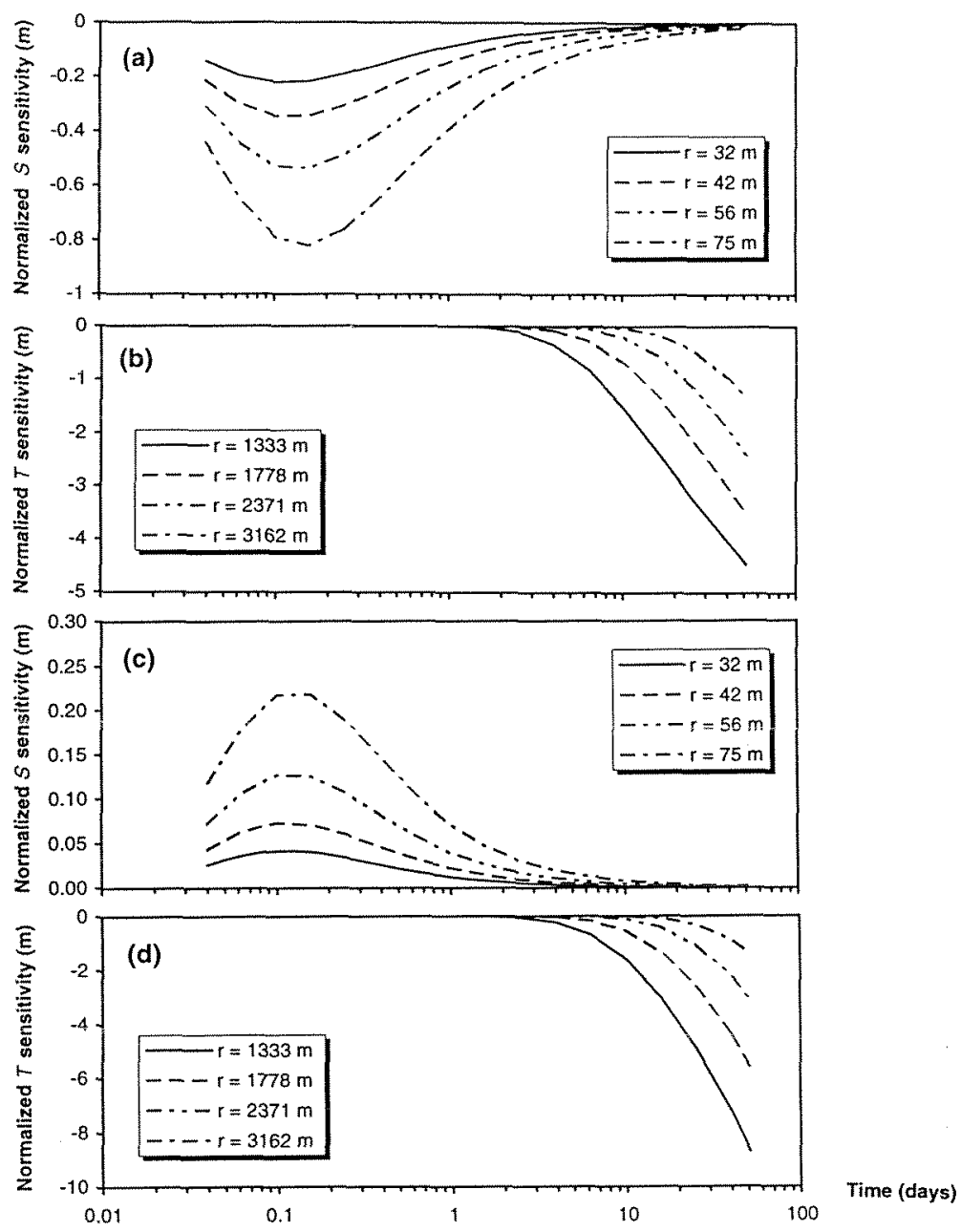

Fig. 8 Temporal change in normalized sensitivity of drawdowns in (a) inner and (b) outer zones to storativity and in (c) inner and (d) outer zones to transmissivity at Cottam. 
The zone boundary was then increased to more than $1000 \mathrm{~m}$ and the storativity sensitivity features of the outer zone investigated. Figure 8(b) shows the sensitivity when the zone started at 1333, 1778, 2371 and $3162 \mathrm{~m}$, respectively. The influence of the outer zone on the drawdown gradually decreased as the zone became more distant. Concurrently, the overlapping of the periods of the observation and sensitivity decreased when the outer zone gradually became more distant. For example, only four or five readings (Fig. 6(a)) were taken in the period during which the outer zone starting at $2371 \mathrm{~m}$ became significantly sensitive. The estimated storativity may thus not reflect the storativity of much of the aquifer beyond that distance.

The corresponding transmissivity sensitivities are presented in Figs 8(c) and $8(\mathrm{~d})$. The general trends are seen to be the same as for storativity. Detailed discussion is omitted.

The above discussion demonstrated that the estimated parameters might not reflect the features of much of the inner zone within $75 \mathrm{~m}$ or of the outer zone starting at $2371 \mathrm{~m}$. Although it is difficult to say exactly which portions of the aquifer the estimated parameters did represent, it seems reasonable to suggest that they represented mainly the aquifer features between roughly 100 and $2000 \mathrm{~m}$.

For a particular inverse method, it may be possible to work out a sensitivity criterion; the zone's features can be reflected only when the sensitivity of the zone is larger than the criterion. Therefore, the portion which can be represented by the evaluated parameters may be more precisely estimated. This is a topic for future investigation.

The drawdowns at $1333,1778,2371$ and $3162 \mathrm{~m}$ from the pumping well were calculated to be $14.89,11.37,8.08$ and $5.20 \mathrm{~m}$. It can be seen that there was substantial drawdown even at $3162 \mathrm{~m}$, although the estimated parameters may reflect little of the aquifer features at such a distance.

When the parameter sensitivity of the outer zone was examined, it was assumed that this zone was infinite. If it were of limited size, the sensitivity would probably be much smaller and the estimated parameters would be much less representative of the features of the limited zone. Also, the sensitivity analysis concerned only the location of the zone, not its parameter values. If the parameters were different from those of the main portion of the aquifer, then the area represented by the estimated parameters would be different. More detailed discussion about this can be found in Jiao (1993).

The above approach may be also useful in well-spacing design in a regional hydrogeological survey. For some hydrogeological projects, detailed hydraulic information about an aquifer is required and several pumping tests are needed to understand the spatial distribution of the aquifer features. There is often the problem of choosing the distance between the pumping wells or the test sites. The well distance is also a traditional issue for water supply in a well field. The radial distance at which the drawdown is approximately zero is considered to be the 'radius of influence' (Driscoll, 1987) and the well distance is considered to be double the radius of influence. For parameter estimation, the 
well distance should be double the radial distance at which the parameter sensitivity is zero or so small that the aquifer features cannot be reflected by a single pumping well.

\section{Investigation of anomalous readings}

In the discussion above, the aquifer was assumed to be homogeneous and the possible area represented by the estimated uniform parameters was discussed. However, as explained previously, the observed drawdown being satisfactorily matched by a standard model does not prove that the aquifer is homogeneous. The implication of anomalous drawdowns on aquifer features will now be examined.

If the drawdowns in Fig. 6(a) are carefully examined, there is some disparity between the observed and calculated values at about 12 days. Generally speaking, disparity can be caused by a change of pumping rate, the influence of boundaries, the interference of other wells, as well as aquifer heterogeneities. For the Cottam case, the rate was almost constant. The westward aquifer boundary was over $10 \mathrm{~km}$ away. The nearest pumping well was $8 \mathrm{~km}$ away (Rushton \& Bishop, 1993). It seems impossible for the boundary or well interference to have caused the disparity at 12 days. Most probably, it was caused by aquifer heterogeneities. If so, these anomalous points might imply the existence of anomalous zones.

The radial numerical model including a less permeable annular zone (similar to the configuration in Fig. 1(b)) was used to fit the observed drawdown at Cottam. The parameters to be optimized were thus four in number, two for the background aquifer and two for the zone. The location of the zone was estimated by trial and error. Because the most anomalous data point appeared at about 12 days, the possible anomalous zone could be quite far from the pumping well. After several trials, with the zone located between 316 and $1000 \mathrm{~m}$, the estimated parameters led to a very small objective function. The estimated parameters and the objective function were $T_{b}=75.97 \mathrm{~m}^{2} \mathrm{day}^{-1}, \quad S_{b}=3.30 \times 10^{-4}, \quad T_{a}=44.08 \mathrm{~m}^{2} \mathrm{day}^{-1}$, $S_{a}=4.59 \times 10^{-4}$, obj. $=2.40$.

The improvement in fit is shown in Fig. 6(b). Although the drawdowns can be 'satisfactorily' fitted by a model with uniform parameters $T=54.34$ $\mathrm{m}^{2}$ day $^{-1}$ and $S=3.80 \times 10^{-4}$ (Fig. 6(a)), the fit can be improved by a model using a more permeable aquifer but with a zone about $700 \mathrm{~m}$ wide and with about $42 \%$ less transmissivity (Fig. 6(b)).

The time during which the drawdown is sensitive to an anomalous zone is very short. The information about such a zone, even when it is substantial and has different flow properties, can be easily missed. For the data at Cottam, if the anomalous point at about 12.6 days is missed (Fig. 6(a)), there seems no way of identifying the anomalous zone, since the rest of the data points can be almost perfectly fitted by a model with uniform parameters. Therefore, in a 
real pumping test, any anomalous points should not be ignored, but should be examined carefully.

It may be argued that the effect of the heterogeneities for the Cottam case is very subtle and it does not seem necessary to invoke the analysis, but the basic approach is believed to be of general use in the case when the disparity in drawdown is significant. It may also be argued that there are uncertainties for the interpretation of the anomalous zone. Different combinations of permeability, size and location of an anomalous zone may produce similar influence on drawdown. For a particular aquifer, however, prior geological evidence can reduce the uncertainties. For this case study, the geological map (Fig. 5) shows that the nearest boundaries to Cottam are faults. It is quite possible that the two faults form a less permeable zone. It should be pointed out that the location and shape of a real zone may be distorted when a radial model is used. Thus, Rushton (1978) demonstrated that, in a particular case study, a straight-line impermeable boundary at a distance of $2.5 \mathrm{~km}$ gave results almost identical to those of a circular one at $4.75 \mathrm{~km}$. Therefore, the approach above cannot give the exact information on an anomalous zone, but it would be helpful in better understanding the hydrogeological conditions of an aquifer.

\section{DISCUSSION AND CONCLUSIONS}

After parameters have been estimated, further research should be carried out to understand the physical significance of the estimated parameters. Some important information about what portions of an aquifer the parameters represent can be obtained by performing a sensitivity analysis. The Cottam case study shows that the parameters estimated from the pumping data over 46 days may not represent the aquifer features beyond $2000 \mathrm{~m}$. This approach is of general significance and is recommended for other pumping test design and data analysis. For a particular pumping test, the size of the aquifer represented by the estimated parameters depends on the aquifer parameters ( $T$ and $S$ ) and the test design (pumping period, pumping rate, location of observation well, etc.). By performing sensitivity analysis using some rough parameter values in advance, a test can be deliberately designed so that the sensitivity behaviour in a zone of particular interest can be best displayed in the observation well. After the test has finished and the parameters have been estimated, a sensitivity analysis should be performed again using the actual parameters, so that their physical implications can be further understood.

The above approach may also be useful in designing the distance between pumping wells or test sites in regional hydrogeological surveys. The best well distance should be double the radial distance at which the sensitivity of parameters is so small that the aquifer features beyond it cannot be estimated by a single pumping well.

Drawdown which can be satisfactorily fitted by a model of uniform parameters does not necessarily justify assuming that the aquifer is uniform. It has 
been demonstrated that slightly anomalous readings may be due to large anomalous zones. Any anomalous readings should therefore be carefully examined for indications of possible anomalous zones. When the background transmissivity is very small, as in the case for the Nottingham aquifer, the aquifer parameters may be significantly underestimated if an even less permeable zone is ignored. Although there are uncertainties for the approach described in this paper to give the exact information on an anomalous zone, it would be helpful in better understanding the hydrogeological features of the aquifer.

Acknowledgments The author appreciates some useful suggestions from K. R. Rushton and stimulating discussions with C. D. McElwee. Thanks also go to A. L. H. Gameson and C. Zheng for their criticisms which led to a significant improvement of this paper. The author would also like to thank the two anonymous reviewers for their many useful comments. Acknowledgement is also given to C. M. Lesher who kindly translated the abstract into French.

\section{REFERENCES}

Butler, J. J. (1988) Pumping tests in non-uniform aquifers: The radially symmetric case. J. Hydrol. $101(1 / 4), 15-30$.

Butler, J. J. \& Liu, W. (1993) Pumping tests in non-uniform aquifers: The radially asymmetric case. Wat. Resour. Res. 29(2), 259-269.

Butler, J. J. \& McElwee, C. D. (1990) Variable-rate pumping tests for radially symmetric non-uniform aquifers. Wat. Resour. Res. 26(2), 291-306.

Driscoll, F. G. (1987) Groundwater and Wells. Johnson Division, St. Paul, Minnesota, USA, 242-243.

Jiao, J. J. (1993) Sensitivity features of aquifer parameters and their implications on parameter estimation. $\mathrm{PhD}$ Thesis, School of Civil Engineering, Birmingham University, Birmingham, UK.

McElwee, C. D. (1987) Sensitivity analysis of groundwater models. In: Advances in Transport Phenomena in Porous Media, ed J, Bear \& M. Y. Corapcioglu. NATO Adv. Study Inst. Ser., E, 128, 751-817.

McElwee, C. D. \& Yukler, M. A. (1978) Sensitivity of groundwater models with respect to variations in transmissivity and storage. Wat. Resour. Res. 14, 451-459.

Rushton, K. R. \& Bishop, T. N. (1993) Water resources study of the Nottinghamshire Sherwood Sandstone aquifer system of tastern England. Project Report, School of Civil Engineering, Birmingham University (unpublished;,

Rushton, K. R. \& Chan, Y. K. (1976) A numerical model for pumping test analysis. Proc. Instn Civ. Engrs, Part 2, 61, 281-296.

Received 31 January 1995; accepted 29 May 1995 
